\title{
MÍ́IA E A PRODUÇÃO DO SUJEITO JOGADOR DE FUTEBOL PROFISSIONAL ${ }^{\star}$
}

\author{
http://dx.doi.org/10.1590/1984-0292/1243
}

\author{
Marcos Daou ${ }^{I} \star \star$, Neuza Maria de Fátima Guareschil ${ }^{I I}$, Marcos Adegas de Azambuja ${ }^{I}$ \\ ${ }^{I}$ Centro Universitário Franciscano, Santa Maria, RS, Brasil \\ ${ }^{\text {II }}$ Universidade Federal do Rio Grande do Sul, Porto Alegre, RS - Brasil
}

\section{RESUMO}

Este artigo tem como objetivo visibilizar e problematizar a constituição do sujeito jogador de futebol profissional na sociedade contemporânea. Como ferramenta metodológica, utilizou-se a análise das práticas discursivas provenientes de materiais midiáticos, articuladas com as regularidades de enunciados construídos pelos campos de conhecimento na produção dos modos de subjetivação deste profissional. Para a análise, selecionou-se o material proveniente da mídia impressa - Jornal Zero Hora, de Porto Alegre, especialmente, em um período que caracterizou-se pelo surgimento de um atleta jovem na categoria profissional. Como resultado, pode ser visibilizado que o jogador de futebol profissional é constituido na contemporaneidade pelos modos de subjetivação através dos imperativos dos investimentos técnicos e do lucro. O sujeito é submetido a intensa produção de metodologias dos campos de saber para aperfeiçoamento para um alto-rendimento e por consequência estar de acordo com as exigências de qualificações do mercado profissional.

Palavras-chave: modos de subjetivação; discurso da mídia; jogador de futebol profissional.

\section{Media AND THE PRODUCTION OF THE PROFESSIONAL SOCCER PLAYER}

\begin{abstract}
This paper aims to visualize and problematize the constitution of the professional football player in contemporary society. As a methodological tool, it is used to analysis the discursive practices from media materials, articulated with the regularities of statements constructed by knowledge fields in the production of professional modes of subjectivity. It was selected for analysis, a media material came from diaries, especially the period characterized by the emergence of a young athlete in the professional category and have earned attention from media. As a result, it can be visualized that the contemporary professional soccer player is composed by the modes of subjectivity through the imperatives of technical investment and profit on body. It is remarkably seen the production of methodological knowledge on athletes, that turns to a high performance.

Keywords: modes of subjectivity; media discourse; professional soccer player.

\footnotetext{
$\star$ Fonte de financiamento recebido no desenvolvimento do trabalho: CAPES.

$\star \star$ Endereço para correspondência: Centro Universitário Franciscano, Curso de Psicologia. Av. Silva Jardim, 1175 - Curso de Psicologia, prédio 17, Conjunto III - Nossa Senhora do Rosário. 97010491 - Santa Maria, RS - Brasil.

E-mail:m.daou@hotmail.com,nmguares@gmail.com,m_adegas@yahoo.com.br.
} 
Este artigo tem como objetivo principal mostrar e problematizar como o jogador de futebol se constitui num profissional ${ }^{1}$ a partir da configuração do futebol na sociedade contemporânea. Para isso, partiu-se da visibilização de algumas formas da prática esportiva com a bola que confluíram para formalizar o futebol como um esporte profissional e regulamentado, apresentado na contemporaneidade. Atualmente, o futebol reveste-se das características de uma lógica mercadológica, incidindo sobre este esporte atravessamentos de campos do saber e de relações de poder distintos que constroem o modo de ser jogador. A construção do jogador profissional acontece a partir de investimentos articulados de diferentes campos sociais na busca do aperfeiçoamento técnico, corporal e comportamental de atletas, que visam o alto rendimento e à otimização de resultados.

Para a discussão sobre a constituição do sujeito jogador profissional de futebol, elegeu-se o discurso da mídia impressa, mais especificamente, as notícias e comentários do caderno de esportes do jornal Zero $\operatorname{Hora}^{2}(\mathrm{ZH})$ durante uma semana. Utilizou-se a análise das práticas discursivas desse material midiático em articulação com as regularidades construídas por determinados campos de conhecimento na produção de enunciados que constituem os modos de subjetivação do jogador profissional de futebol. Para esta análise do material midiático, selecionamos, especialmente, a semana que se estendeu de 20 a dia 28 de novembro de 2006. O critério de escolha desse período fundamenta-se no fato de que, naquela semana, o jornal publicou o sucesso de um jovem jogador de futebol, mostrando o curto tempo deste profissional entre as categorias de base e a iminência de se tornar mais uma das maiores promessas no ramo, podendo, deste modo, o Brasil apresentar ao mundo mais um dos fenômenos desse esporte.

Aquela semana caracterizou-se como o período de escolha dos nomes que estariam na listagem dos atletas que integrariam a delegação do Esporte Clube Internacional ${ }^{3}$ para a disputa do Campeonato Mundial Interclubes, no Japão, mostrando a estreia de um jovem jogador, de apenas 17 anos, no time profissional, passando das categorias de base do clube, com esperança de êxito na maior competição da história. Por meio do discurso da mídia, objetivamos visibilizar como são produzidos os sentidos que constroem os enunciados que passam a se configurar na sociedade - os modos de produção desse profissional na contemporaneidade.

\section{O disCURSO dA MídIA E A PRODUÇÃo de SENTIDO}

A mídia é entendida aqui como uma instância central da sociedade contemporânea por produzir cultura, veicular e construir significados e representações. Consideramos que a mídia é um lugar privilegiado de criação e circulação de sentidos que operam na formação de identidades, bem como na produção de diferenças. Entendemos que os significados visibilizados pelo discurso midiático não só produzem verdades sobre os objetos de que falam, como também produzem os sujeitos desses objetos. Para Fischer (2002), por meio da visibilidade de situações, a mídia torna-se um poderoso meio de produção e circulação de 
valores, concepções e representações relacionados a um aprendizado cotidiano sobre quem somos, o que devemos fazer, como devemos nos educar e de que maneira devemos ver as pessoas.

Entendendo a mídia como constituinte da cultura, como produtora e formadora de modos de ser e de viver na contemporaneidade, pensamos nela como construtora de verdades por meio do discurso que veicula. Tal discurso é atravessado por várias lógicas, dentre as quais, as do consumo, do mercado e da tecnologia, as quais servem de legitimação para consolidar estilos de vida. Em sua leitura sobre a produção e importância da mídia na formação de subjetividades, Pelbart (2003, p. 20) afirma: "o que nos é vendido o tempo todo, senão maneiras de ver, de sentir, de pensar, de perceber, de morar e de vestir. O fato é que consumimos mais do que bens: formas de vida".

Desse modo, a mídia configura-se na contemporaneidade como grande potência de estratégias educativas informacionais. Em confluência com essa ideia sobre mídia, Fischer (2001a) alerta sobre a importância que os meios de comunicação, no Brasil e no mundo, vêm assumindo como lugar de circulação de vários campos de saberes e também de produção de um campo de saber próprio. A autora considera que a questão da mídia como produtora de verdades necessita de uma análise que possa nos situar no contexto em que a imagem, ou aparecer na TV, em jornais e revistas, se configura em relações de poder, produzindo efeitos específicos nas pessoas, construindo um tipo especial de verdade. Segundo a mesma autora, a mídia não apenas veicula, como também constrói discurso e produz significados e identidades.

Como fatos ilustrativos, Guareschi e Biz (2005) referem a importância que os meios comunicacionais têm assumido na relação das pessoas nos dias de hoje - o tempo médio que os brasileiros passam na frente da televisão é de quase quatro horas. Se nos reportarmos à população mais carente, a média, em vilas periféricas de Porto Alegre, conforme os mesmos autores, chega a seis horas; e, nos casos mais extremos, nas casas de crianças cujos pais e mães têm receio em soltá-las pela rua, a televisão permanece ligada durante nove horas. Com isso, a mídia vem se configurando como outra possibilidade pedagógica e de relação na sociedade. Formaliza-se em um personagem com o qual nos relacionamos cotidianamente. Fischer (2002) afirma que, em relação à escola, à família, aos amigos e aos meios de comunicação, a mídia vem se estabelecendo com uma importância maior na constituição dos sujeitos.

A mídia, conforme Guareschi e Biz (2005), ocupa grande proporção e importância no cotidiano; ela contribui na construção de realidades, cria e legitima valores que levam as pessoas a agir. Assim, torna-se responsável pela pauta das discussões diárias entre as pessoas, formalizando-se significativamente na produção de subjetividades. A proporção adquirida pela mídia na sociedade contemporânea tem relação muito próxima com a emergência das novas tecnologias. Os mesmos autores afirmam que o avanço tecnológico foi responsável por trazer modificações em três dimensões essenciais para os seres humanos: "da distância, do espaço e do tempo" (GUARESCHI; BIZ, 2005, p. 46). O mundo moderno estru- 
tura-se na rapidez de informação, no encurtamento das distâncias, na facilidade de acesso, na espetacularização dos acontecimentos, no investimento maciço do capital regulando as atmosferas de vida e na promulgação do consumo. Consumo é aqui entendido não só como de bens materiais, como também consumo do corpo, de formas de vida que geram prazer, proporcionando satisfação imediata, como afirma Lipovetsky (2004).

Para Virilio (1996a, 1996b), a tecnologia nos afeta independentemente do que fazemos. Atinge-nos principalmente na aceleração. Se amplificamos a questão da aceleração e a transpomos para a prática diária das informações, o que se cria é um desinteresse no conteúdo do que sabemos, mas um interesse em saber mais rápido do que os outros. Segundo o autor, a sociedade está perdendo em conteúdo e ganhando em rapidez. Ao direcionarmo-nos para o papel do jornalismo e sua veiculação de notícias, nesta sociedade da rapidez, estamos menos preocupados em explicar e interpretar do que em divulgar a informação o mais rapidamente possível.

Fischer (2001b) diz que a mídia, por constituir-se em uma instância produtora de subjetividades, é entendida como a experiência que o sujeito faz de si mesmo. Dessa forma, por meio da circulação de realidades e verdades, o sujeito experimenta situações, sentimentos, possibilidades que servem para produzi-lo. A autora refere que, entendendo a mídia como produtora de sujeitos, os meios de comunicação são veículos de circulação e produção de valores e concepções, relacionados a um aprendizado cotidiano de quem nós somos. Assim, existe a possibilidade de entender a mídia como um local de veiculação de discursos, os quais estão associados a modos de ser, pensar e se relacionar com o mundo.

\section{Sobre QUAL CONTEXTO DA PESQUiSa SE FALA}

Analisando o discurso da mídia como produtora de sujeitos jogadores de futebol profissional, Carvalho (2005) afirma que o espaço destinado para este esporte nos periódicos de Campinas possui uma abrangência de $78 \%$ do total do caderno de esportes. Por intermédio do conteúdo visibilizado sistematicamente e com tal abrangência, contribui-se para a construção do futebol como instituição esportiva, mas, principalmente, para a produção dos modos de ser jogador de futebol profissional.

Antunes (2004) afirma que, com a invenção da imprensa esportiva no começo do século passado, o jornal transformou o jogo de futebol em notícia, ampliando sua repercussão e importância na vida das cidades e do país. Com esse invento, a promoção do futebol, o falar sobre o esporte, fez com que crescesse o interesse da população em praticá-lo e vê-lo, contribuindo diretamente para a constituição do fenômeno de massa que é hoje. O mesmo autor, referindo-se ao jornalista Mario Filho, ${ }^{4}$ menciona que este, na década de 50, ao acrescentar dramatismo e paixão nas reportagens sobre o futebol, causou mudanças nesse esporte, contribuindo para a aproximação do torcedor com o jogador e o clube e fazendo com que o profissional passasse a ser considerado, muitas vezes, como ídolo ou superstar. 
Aproveitando-se da figura do jogador de futebol como grande astro na contemporaneidade e com papel destacado para os processos de identificação e subjetivação, King, citado por Simpson (1994, p. 21), afirma que:

Os astros detêm um importante controle sobre a representação das pessoas em sociedade, e a forma como eles são representados nos meios de comunicação de massa irá exercer algum tipo de influência (mesmo que apenas de reforço) sobre seu modo de ser em sociedade. Os astros ocupam uma posição privilegiada na definição dos papéis e tipos sociais, e isso acarreta consequências reais em termos de como as pessoas acham que podem e devem se comportar.

A partir dessa concepção de análise sobre o discurso da mídia, Pilotto (2003) comenta que a fabricação de ídolos esportivos ocorre em um processo que envolve publicação sistemática de artigos, textos publicitários, narração de jogos, comentários de especialistas, pondo em destaque qualidades e atributos distintos desses sujeitos, que os configuram como especiais. Dessa forma, a mídia, ao expor demasiadamente atletas, ao falar sobre esportes, ao visibilizar as notícias desse espectro, cria verdades e realidades, produzindo o sujeito jogador profissional do futebol.

A importância do discurso da mídia para a configuração do futebol contemporâneo e para a produção do sujeito jogador profissional desse esporte foi o ponto de partida para a análise das reportagens da mídia impressa do caderno de esportes do jornal Zero Hora. O objetivo foi buscar o que estava sendo enunciado pelas regularidades do discurso midiático sobre essa prática. Consideramos que a análise desse material nos possibilita algumas reflexões sobre a prática do futebol e a produção dos modos de ser jogador profissional desse esporte.

\section{Notas METOdOlÓGICAS PARA O DESENHO dO ESTUdO}

A partir da análise de crônicas, reportagens, comentários de jornalistas, cronistas e colunistas, buscamos identificar os sentidos produzidos pelo discurso da mídia na construção de enunciados que, em articulação com campos de conhecimentos distintos, posicionam os sujeitos como jogadores profissionais de futebol. Esse exercício é constituído a partir da visibilização de quem fala, de como se fala, do que se fala e de que lugar se fala.

No quadro abaixo, destacamos parte de alguns materiais utilizados nesta pesquisa, a fim de exemplificarmos a forma como os organizamos para análise dos enunciados provenientes do discurso midiático. Por meio da análise, visualizou-se a construção de dois enunciados principais que remetem aos significados de como se constitui hoje o jogador profissional de futebol. Esses enunciados são: o corpo da técnica e o corpo para o lucro. O corpo da técnica é entendido como o processo de subjetivação em que o jogador de futebol é tomado como objeto por campos de saber através de técnicas que buscam o aperfeiçoamento dos corpos orgânicos, físico 
e psicológico. O corpo para o lucro evidencia o processo de subjetivação do atleta como parte do sistema mercadológico do futebol, mediante investimentos para produzi-lo, deixando-o apto para a comercialização e, consequentemente, para o lucro.

\section{O CORPO DA TÉCNICA}

No cenário do futebol contemporâneo, a questão do corpo vai ao encontro da lógica que rege a sociedade do consumo. Investe-se no corpo para se extrair a maior potencialidade, o melhor rendimento; busca-se o aperfeiçoamento constante que, por consequência, gere maior produção. Para Cagliani (2005), as marcas corporais da sociedade contemporânea fundam-se na lógica mercadológica, expressa pela busca da lucratividade, na qual o aperfeiçoamento técnico procura a maior produção em menor tempo. Nos modos de ser jogador de futebol profissional, o corpo do atleta é tomado com o objetivo de deixá-lo apto para o enfrentamento da rotina de treinos e jogos, preparando-o para produzir mais em menor tempo e, se possível, na maior potência física possível. O corpo da técnica caracteriza-se pelo investimento corporal na busca do aumento de produção para obtenção do maior rendimento possível e pelo uso desse rendimento do corpo pelo mercado do futebol.

Instaura-se, a partir dessa busca de rendimento, uma tecnologia de vida que impera sobre o modo de ser jogador profissional de futebol. Segundo Foucault (1991; 2005), trata-se de uma tecnologia para evidenciar a confluência de dispositivos, situações, experiências que fazem com que as pessoas se subjetivem, construindo-se modos de ser, falar, pensar, enfim, modos de viver. Aos corpos dos profissionais do futebol são atribuídos deveres e obrigações na busca de ser o melhor jogador, ganhar mais dinheiro, vencer campeonatos. Essas atribuições imperam sobre a forma de se portar e ser, de tal maneira que não se consegue mais pensar fora dessas atribuições para a construção de uma forma de viver.

As técnicas que trabalham o corpo também falam de uma disciplina atlética que governam os modos de ser da profissão do jogador de futebol. A partir da análise do discurso midiático, a conformação do corpo da técnica pôde ser visibilizada mediante a incidência de, pelo menos, três formas de tecnologias de investimento sobre o corpo do jogador de futebol profissional: "tecnologia de regulação orgânica", "lapidação do corpo pelo saber da Educação Física e da Medicina" e "normatização do comportamento pelo saber psicológico".

As tecnologias orgânicas no esporte do futebol são utilizadas, por exemplo, para a manutenção das dosagens enzimáticas e metabólicas e para o controle alimentar. São extremamente importantes para o desempenho funcional atlético, conforme menciona Powers (POWERS; HOWLEY, 2000). Na busca da homeostase orgânica, articulam-se os saberes da Medicina, da Nutrição, da Fisiologia, entre outros, para o enfrentamento das exigências atléticas a que os jogadores de futebol são submetidos. Saberes do campo de conhecimento da Nutrição contribuem nas técnicas orgânicas, com a implementação de dietas alimentares que oferecem fontes de energia ideais para ativar e manter o corpo energeticamente apto para as exigências do treinamento, visando ao desempenho físico durante treinos e jogos. 
Conforme trazem Guerra, Soares e Burini (2001), o jogador de futebol treina em intensidade moderada e alta. Devido a tal exigência, tem necessidades energéticas diárias entre 3.150 a $4.300 \mathrm{Kcal}$. Dessa maneira, articulando-se a saberes da ciência da Nutrição, a mídia visibiliza a importância de controlar a alimentação dos atletas, de forma que estes se adaptem a padrões alimentícios para apresentar o melhor rendimento possível. $\mathrm{Na}$ frase do preparador físico manifesta logo a seguir, explicita-se a intenção que os clubes de futebol têm de cercar os atletas de cuidados alimentares para que estejam aptos para o enfrentamento da rotina de treinos: "como o clube oferece três refeições diárias, fica mais fácil controlar a alimentação do grupo. Quando o treinamento ocorre em dois turnos, os jogadores tomam café da manhã e almoçam no estádio" (RECOMENDAÇÃO..., 2006, p. 50). Mostra-se, assim, a importância de controlar a alimentação para potencializar os resultados, afastando-se efeitos que uma má alimentação poderia acarretar. Constrói-se, então, a necessidade de regular a alimentação do jogador para que o fator orgânico não prejudique seu rendimento atlético.

Legitimando a compreensão sobre a necessidade orgânica do jogador de futebol, Guerra, Soares e Burini (2001) referem que a qualidade e a quantidade de treinos influenciam no gasto energético do jogador; logo; faz-se necessário um acompanhamento alimentar para maximizar a performance atlética. Para os autores, o glicogênio muscular tem fundamental importância na produção de energia durante um exercício. Articulando-se a esse saber, o discurso da mídia formaliza e legitima um padrão de alimentação adequado para suplantar a exigência do trabalho, construindo o sentido de que os atletas devem manter uma dieta específica para que deles se extraiam os melhores resultados. Esse sentido, da necessidade orgânica do jogador de futebol, produzida pelo discurso da mídia, fica explícito na frase do preparador físico da equipe: "Elaborado pelas nutricionistas, o cardápio inclui a quantidade recomendada de carboidratos e proteínas" (RECOMENDAÇÃO..., 2006, p. 50). Sendo assim, a manutenção do padrão disciplinar na alimentação dos jogadores direciona-se pela demanda orgânica que possa sustentar um rendimento físico cada vez melhor.

Por meio da disciplina alimentar, evidenciam-se os sentidos produzidos pelo discurso da mídia que subjetivam o modo como o jogador deve pensar seu modo de vida alimentar. Esse modo de alimentação que se produz passa a ser um controle nutricional que mantém sua performance esportiva. A não-disciplina alimentar é indicada como aquilo que leva a um aumento de peso e a uma baixa produtividade. Essa questão fica evidenciada pela frase do preparador físico ao se referir sobre a importância em seguir disciplinarmente a dieta elaborada pela equipe: "Fritas e refrigerante só uma vez por semana. $\mathrm{O}$ trabalho de reforço muscular inclui um rígido controle sobre a alimentação do jogador" (RECOMENDAÇÃO..., 2006, p. 50).

As tecnologias que subjetivam o modo do jogador cuidar do seu corpo são mostradas pela mídia como imprescindíveis na conformação do corpo desse profissional, pois, para render tudo o que dele se espera, o atleta deve estar organicamente regulado dentro do planejamento da comissão técnica, segundo os 
objetivos do clube. Assim, o controle alimentar, como exemplo de tecnologia orgânica, produz um profissional de futebol cujo corpo é entendido majoritariamente como um lugar de investimento da técnica para sua capacitação atlética.

Outra tecnologia de investimento sobre o corpo do jogador profissional é articulada no discurso da mídia pelos saberes dos campos de conhecimento da Educação Física e da Medicina, especialmente no que se refere aos aspectos de treinamento físico, comportamento motor e fisiológico. Metodologias de treinamento sofisticadas e inovadoras desses campos de saber são utilizadas como tecnologias para trabalhar o corpo do jogador, ou seja, métodos técnico-científicos são empregados na busca de um alto rendimento. Essas tecnologias visam a maior precisão do corpo do jogador, produzindo um modo de subjetivação na forma como ele passa a pensar o corpo - uma estrutura que possa buscar sempre um desempenho cada vez melhor. A importância da tecnologia do desenvolvimento atlético baseado na compreensão física visibilizadas pela mídia encontra-se na frase do colunista: "Os jogadores estão recebendo tratamento especial para ganhar massa muscular. [...] é absolutamente necessário no futebol de hoje, em que o preparo físico prevalece sobre a técnica".

A predominância do estudo do desempenho físico ${ }^{5}$ atravessa a preparação dos atletas na busca de melhores rendimentos de uma forma decisiva, de maneira a acelerar o processo de preparação e de recuperação dos atletas. Os artifícios instaurados na rotina de treinamentos do futebol visam a desenvolver, além da capacidade física dos profissionais, uma disciplina para que o jogador possa controlar a qualificação de seu corpo para o esporte.

Essa exigência é visibilizada no discurso da mídia na frase do colunista quando este se refere à importância do trabalho físico e à necessidade da disciplina de treinos para a construção de um corpo forte, apto às exigências do esporte: "Futebol é choque. O jogador precisa estar preparado para aguentar as trombadas". Ou, ainda, nas palavras de outro colunista, quando manifesta o resultado que a não-adesão a essa formatação física ocasiona: "Domingo era visível a diferença de peso e estatura entre os jogadores. O resultado era inevitável: nas divididas, quase sempre o jogador do Inter acabava no chão".

O regime de treinamentos que visam ao aperfeiçoamento constante do corpo dos jogadores pode fazer com que estes encarem a insubmissão à busca constante do rendimento físico do corpo como ameaça de um possível desligamento desse esporte. O discurso da mídia visibiliza a promoção dos jogadores com boa capacitação física de alto rendimento atlético, mostrando os benefícios que eles podem conseguir ao se submeterem às exigências físicas, o que pode ser visto nas palavras do atleta: publicada na matéria "O verdadeiro pato" (VERDADEIRO... 2006, p. 46). "Não tenho dúvidas quanto aos benefícios do reforço muscular. Melhorei o arranque e consigo proteger a bola com mais eficiência, além de chutar mais forte".

A conformação desse corpo da técnica pelos investimentos das tecnologias para uma perfeita regulação do orgânico e para a lapidação do corpo na preparação do físico é consolidada com as tecnologias do campo de saber psicológico. A Psicologia investe na produção desse sujeito, focalizando a atuação na escuta 
de aspectos da sua vida que possam vir a incidir sobre o rendimento profissional. Essa escuta psicológica trabalha produzindo dicotomias entre os aspectos emocionais pessoais e a performance da vida profissional.

Weinberg e Gould (2001) definem o saber da Psicologia no campo do esporte como o estudo científico dos sujeitos e de seus respectivos comportamentos, no contexto esportivo, aplicando-se os conhecimentos na obtenção de melhores rendimentos. O objetivo das técnicas psicológicas é minimizar o efeito de questões emocionais no rendimento esportivo, em que questões psíquicas são trabalhadas com vistas ao aumento de performance. Desta forma, a mídia articula-se ao saber psicológico, visibilizando a importância dos aspectos emocionais dos jogadores serem trabalhados para o bom desempenho nos jogos. Esse sentido produzido pelo discurso da mídia é evidenciado na frase de um treinador, a partir da reportagem "Habemus Pato" (HABEMUS..., 2006, p. 44) quando se refere às possibilidades de um profissional jovem não possuir maturidade para lidar com algum tipo de interferência sobre sua vida: “[...] é preciso deixá-lo livre, sem o peso da cobrança. A pressão do profissional é muito diferente".

Ao veicular a necessidade das tecnologias psicológicas no trabalho com o jogador de futebol, o discurso da mídia constrói a importância da utilização desse campo de saber na produção dos modos como o profissional se constitui como sujeito desse esporte. Utilizando-se do saber da Psicologia, o discurso da mídia circula os sentidos de que não basta somente ter qualificação técnica, excelente rendimento físico e composição orgânica perfeita, mas que é também necessário que o jogador esteja livre de complicações emocionais. Esse sentido é produzido pela frase do colunista, na matéria intitulada "A boa cabeça" (BOA..., 2006, p. 10), quando se refere ao conjunto de capacidades do atleta como condição para o êxito profissional: "Se for tudo aquilo, pelo desembaraço, qualidade técnica e comovente simplicidade de encarar os fatos (isso que se chama de cabeça boa), tem tudo pra tentar a façanha no mundial".

Assim, o discurso midiático atribui ao trabalho do campo de saber da Psicologia a responsabilidade de poder conter efeitos emocionais advindos de situações diversas da vida do jogador que possam intervir em conquistas esportivas ou na manutenção dos resultados positivos, como fica evidenciado na frase do treinador na matéria intitulada "Era jogo para Pato" (ERA..., 2006, p. 02): "seguiremos trabalhando a cabeça e dizendo que é mais um no grupo" (SEGUIREMOS..., 2006, p. 2). Por meio dessas articulações do discurso da mídia com o campo psicológico, podem-se identificar os modos de o profissional se subjetivar como sujeito jogador, junto a perfeita regulação do orgânico e a lapidação do corpo na preparação do físico.

A construção dos modos de subjetivação do jogador de futebol profissional que configura esse esporte na sociedade contemporânea encontra, portanto, no enunciado do corpo da técnica, não só a lógica de estruturação e funcionamento desse esporte, mas a forma de inserção e sustentação para competir e lucrar no mercado do futebol. Assim, a produção da construção do corpo da técnica passa a produzir também a construção do corpo para o lucro. 


\section{O CORPO PARA O LUCRO}

Na produção do mercado do futebol, os clubes têm como uma das preocupações centrais o investimento na produção de jogadores, principalmente no que diz respeito ao corpo, no que possa ajudar no rendimento em competição e no sucesso do profissional. Os investimentos feitos nos corpos dos jogadores e visibilizados pelo discurso da mídia são produzidos a partir das tecnologias que incidem sobre o corpo atlético, visando a aperfeiçoá-lo, não só para as exigências atléticas, como também para o desenvolvimento do profissional. Preparando os corpos tecnicamente para o rendimento esportivo, essas tecnologias buscam um corpo que possa competir no mercado do futebol, principalmente para que traga lucratividade para o clube. Ou seja, além do rendimento atlético cedido pelo profissional ao clube, o corpo, produzido como forte e bem preparado, também passa a ser um produto para o futebol.

Sobre esse mercado esportivo, Fraga (2000) discute que os investidores exigirão dos atletas rendimentos compatíveis com o capital neles investido e que a quantidade de incentivos endereçados aos jogadores estará vinculada à possibilidade de conquistas esportivas. Tais conquistas não necessariamente vão se restringir ao desempenho nas competições; elas também vão se dar pelo modo como é produzido e apresentado o jogador de futebol profissional. Nesse caso, a forma como é apresentado o corpo do jogador também se torna um produto envolvido nas conquistas do esporte. Como exemplo, basta ater-se à grande quantidade de comerciais realizados com as imagens dos jogadores de futebol que atraem consumidores, compradores de diferentes populações, gerando lucro para o jogador e para o clube.

Leoncini e Silva (2005), em relação ao mercado do futebol e à movimentação de capital nesse esporte, citam dados do relatório final do plano de modernização do futebol brasileiro, da Fundação Getúlio Vargas, os quais afirmam que, em âmbito mundial, o futebol movimenta anualmente cerca de 250 bilhões de dólares. Nesse movimento de capital financeiro, incluem-se as somas provenientes principalmente da mídia, dos clubes, das federações, das indústrias de equipamentos esportivos, de patrocinadores e de agentes direta ou indiretamente envolvidos na produção do incentivo ao lucro no futebol.

$\mathrm{O}$ investimento no mercado do futebol é, também, enfatizado em tempos de copa do mundo, quando grandes patrocinadores se envolvem com esse esporte e, por consequência, muitos jogadores passam a aparecer nos mais diferentes tipos de comercialização de mercadorias. Essa questão é tomada pelo discurso da mídia ao mostrar a distribuição de 591 bilhões de reais, na última Copa do Mundo para a premiação dos vencedores (PREMIAÇÕES..., 2006, online). A partir desse enunciado, passa-se a produzir o sentido sobre o corpo do jogador de futebol como aquilo que atrai e vende para competir na geração de lucros e capital.

Cagliani (2005) afirma que a configuração da sociedade atual está baseada na lógica lucrativa, e pensando o mercado do futebol como um vetor, um eixo desta sociedade, podemos ver os corpos dos jogadores como mais um produto utilizado para legitimar a lógica mercadológica. Os sentidos que a mídia 
produz sobre a utilização do corpo do jogador de futebol, como produto para incentivar o mercado, são um modo de produção do atleta desse esporte. Ao ser subjetivado a partir desses sentidos, o atleta passa a pensar o corpo para além do rendimento dentro de campo, ampliando-o para o modo como ele tem que se posicionar como sujeito jogador de futebol.

Essa produção dos modos de subjetivação do jogador de futebol profissional é ilustrada pela frase do comentarista, sob o enunciado de sua crônica "Surge uma estrela" (SURGE..., 2006, p. 11), ao referir que o rendimento pretendido e valorizado pelo mercado, com o desempenho do corpo atlético, proporciona lucro a partir da avaliação do corpo dos jogadores: "tem muita técnica, velocidade de execução e domina bem todos os fundamentos. Chuta bem com os dois pés, cabeceia bem e tem explosão muscular". Nesse caso, todas essas características, mas principalmente a explosão muscular, são vistas como qualificação do corpo do jogador de futebol profissional que atrai esse mercado.

A produção de sentidos pelo discurso da mídia, em que o corpo do atleta é também um corpo do lucro, um corpo que atrai, é produzida na matéria, "O acerto de pato sai amanhã", nas palavras de um colunista: "O valor da transação chegará aos 11 milhões de euros. Se tornará o mais caro jogador gaúcho de todos os tempos. [...] o atacante é o novo alvo da multinacional para integrar seu time de craques" (ACERTO... 2006, p. 47). A construção de corpos como sendo capazes de gerar lucros e atrair fazem com que todo o mercado econômico da área esportiva se mobilize em busca desses corpos para garantirem lucros. Além dessa produção e mobilização, por parte do mercado econômico, na busca de um corpo que gere lucro e que atraia, o discurso da mídia na atribuição de significados aos sentidos que são produzidos em relação ao corpo, produz, também, modos de o atleta se subjetivar como jogador deste esporte. Ou seja, este passa a pensar que, para ser bom jogador e ter condições para competir, deve-se também ter um corpo que gere lucros e que atraia.

Em uma crônica intitulada "Manual das celebridades" (MANUAL..., 2006, p. 52), o autor remete à produção de cuidados do corpo e às formas de viver das celebridades, sendo estas, em sua maioria, jogadores de futebol: "é um jogo de esconde-esconde, no qual as celebridades fingem que se incomodam com o assédio, mas torcem para que suas extravagâncias sejam divulgadas". Em outro trecho da crônica, o autor refere-se diretamente ao desempenho de um atleta, descrevendo situações em que o jogador deve produzir um determinado modo de vida para se tornar atrativo ao público: "Os milhões começam a chegar às contas. Não é mais possível andar como um desconhecido pelos corredores dos centros comerciais, nem atender todas as ligações que chegam".

Porém, ainda na crônica de celebridades esportivas, o autor indica que o corpo que passa a ser atrativo e que gera lucro se submete também a determinadas situações por ser cobiçado, fato que pode lhe trazer riscos, mas que é lucrativo para outros mercados: "Entram em cena as empresas de segurança. Qualquer passo da celebridade, a partir de agora, tem de ser orientado pelas normas dos agentes especiais" (MANUAL..., 2006, p. 52). Assim, também o discurso da mí- 
dia produz os sentidos que fazem com que o jogador de futebol passe a produzir modos de como planejar e organizar a vida, como o de se proteger, de se precaver, de modificar hábitos cotidianos, ou como circular à vontade em público.

Todas essas produções em relação ao corpo do jogador como um corpo que gera lucro, um corpo capital, também são associadas ao corpo que vence: o corpo do vencedor. Guerra (2005), ao comentar sobre o investimento que uma empresa patrocinadora de uma equipe de futebol realizou para a contratação de um grande jogador, justifica a escolha do atleta pelo fato de este possuir uma das carreiras mais vencedoras do futebol brasileiro, mesmo sendo conhecido como indisciplinado. $\mathrm{O}$ critério de um grande jogador e de um grande vencedor não é só fundamentado no desempenho técnico no esporte, mas também no corpo do jogador que se mostra vencedor nos modos de vida ou na forma como mostra os modos de viver. Esse sentido, produzido pela mídia, de associar o corpo do rendimento ao corpo que vence fica evidenciado, por exemplo, a crônica "Lá vem o Pato", quando o cronista condiciona a atuação vitoriosa ao investimento no atleta: "No seu primeiro jogo como profissional, jogador de 17 anos marca gol e faz jogada de outros dois. Estrela para o Japão mostra porque é diferente e justifica o investimento realizado" (LÁ..., 2006, p. 48). Outro discurso proferido pelo comentarista legitima essa questão ao analisar os desmembramentos que a vitória e a atuação decisiva em uma partida tiveram em termos de modificações contratuais, propiciando maior lucro para o clube com o desempenho desse corpo: "Deu passe de calcanhar, fez gol e acertou um cabeceio na trave. Se não houvesse a renovação do contrato, hoje estaria sendo vendido por uma ninharia de 4 milhões de reais".

Assim, fica visível o modo de produção de ser jogador de futebol - no sentido de que os corpos possam ser pensados para o alto rendimento e geração de lucro e de que as técnicas existentes invistam nesses corpos tendo em vista esses objetivos. Isso vem a subjetivar o jogador profissional de futebol, ou seja: além de se deixar incidir por técnicas que produzem o alto rendimento no corpo e por técnicas de mercado para que esse corpo gere lucro, o jogador também vê se construir em todas estas estratégias o modo de pensar a vida enquanto sujeito jogador de futebol.

Então, por meio da análise do material midiático referenciado para este estudo, fica visibilizada, além da produção do corpo da técnica, atrelado a tecnologias de investimento que produzem esse corpo, também a produção do corpo para o lucro. As tecnologias que regulam o funcionamento orgânico, a lapidação do físico e o trabalho psicológico na busca da excelência para o rendimento esportivo conformam o corpo da técnica para fins da produção de um corpo para o lucro. Tanto o corpo da técnica quanto o corpo para o lucro são mostrados pelo discurso da mídia, que por sua vez contribuem na produção dos sentidos sobre o modo como se deve pensar, ver, ser e entender o jogador de futebol profissional. 


\section{Notas}

${ }^{1}$ Este artigo é proveniente da dissertação de mestrado de Marcos Daou (2007).

${ }^{2}$ Zero Hora é um jornal publicado diariamente, com grande circulação no estado do Rio Grande do Sul. O periódico faz parte do núcleo jornalístico da RBS (Rede Brasil Sul), filiada da Rede Globo de telecomunicações. Como tal, caracteriza-se como forte veículo de comunicação. Apresenta-se editado em cadernos que abordam assuntos do cotidiano, como política, cultura, esportes, etc. Possui colunistas e repórteres que expressam suas opiniões, debatem e noticiam fatos e acontecimentos em nível regional, nacional e internacional.

${ }^{3}$ O Sport Club Internacional foi fundado em 4 de abril de 1909, pelos Irmãos Henrique, José e Luis Poppe, vindos de São Paulo. De família italiana, os irmãos resolveram homenagear seus pais, batizando o clube com o mesmo nome da equipe pertencente à cidade deles: Internazionale de Milão. O clube surgiu devido a constantes negativas que recebiam ao quererem se juntar a algum clube de Porto Alegre. Em virtude disso, resolveram fundar o próprio clube. O internacional é conhecido como clube do povo, pois foi fundado e, primeiramente, frequentado por imigrantes paulistas e por jovens de menor prestígio da sociedade porto-alegrense. Além disso, foi o primeiro a receber em seu quadro social e atlético pessoas negras e de menor poder aquisitivo, em comparação com a agremiação rival, Grêmio Futebol Porto-alegrense.

${ }^{4}$ Mario Filho foi um jornalista carioca que inovou a maneira de se fazer jornalismo esportivo, principalmente nas décadas de 1930 e 1940, por acrescentar sentimentos pessoais nas reportagens que produzia. O Maracanã, estádio de futebol que recebeu a final da Copa do Mundo de 1950, possui o nome deste jornalista em homenagem ao seu trabalho.

${ }^{5}$ Como exemplo de algumas técnicas utilizadas pelas ciências da Medicina, Educação Física e Fisioterapia, que formam este campo, destacam-se: a crioterapia, que atua sobre o corpo para aliviar a fadiga e recuperar a musculatura para a rotina de trabalho; a utilização da prescrição de exercícios por meio da medição do lactato; e o uso do global positioning system (GPS) para se ter maior precisão no rendimento físico dos atletas.

\section{REFERÊNCIAS}

ACERTO de Pato sai amanhã, O. Zero Hora, Porto Alegre, 22 nov. 2006. Caderno de Esportes, p. 47.

ANTUNES, F. M. R. F. Com brasileiro não há quem possa! futebol e identidade nacional em José Lins do Rego, Mario filho e Nelson Rodrigues. São Paulo: UNESP, 2004.

BOA cabeça, A. Zero Hora, Porto Alegre, 27 nov. 2006. Caderno de Esportes, p. 10.

CAGLIANI, B. Corpo, tecnologia e controle: Gattaca e o Homem-máquina. CAOS - Revista Eletrônica de Ciências Sociais, [S.1.], n. 8, p. 7-16, mar. 2005. Disponível em: < http://www.cchla.ufpb.br/caos/biacagliani.pdf>. Acesso em: 02 set. 2013.

CARVALHO, J. M. A chuteira na mídia: a predominância do futebol na imprensa campineira. In: CONGRESSO BRASILEIRO DE CIÊNCIAS DA COMUNICAÇÃO, 28., 2005, Rio de Janeiro. Anais... São Paulo: Intercom, 2005. CD-ROM. 
DAOU, M. Das práticas de esporte com a bola à configuração do futebol na sociedade contemporânea. 2007. Dissertação (Mestrado)_Pontifícia Universidade Católica do Rio Grande do Sul, Porto Alegre, 2007.

FISCHER, R. M. B. Televisão e educação: fluir e pensar a TV. Belo Horizonte: Autêntica, 2001a.

FISCHER, R. M. B. Mídia, estratégias de linguagem e produção de sujeitos. In: CANDAU, V. M. (Org.). Linguagens, espaços e tempos no ensinar e aprender. 2. ed. Rio de Janeiro: DP\&A, 2001b. p. 74-88.

ERA jogo para Pato. Zero Hora, Porto Alegre, 20 nov. 2006. Caderno de Esportes, p. 02 .

FISCHER, R. M. B. O dispositivo pedagógico da mídia: modos de educar na (e pela) TV. Revista Educação e Pesquisa, [S.1.], v. 28, n. 1, p. 151-162, jan./jun. 2002.

FOUCAULT, M. Tecnologias del yo. In: textos afines. Barcelona: Paidós Ibérica, 1991. p. 45-94.

. Tecnologias del yo y otros

FOUCAULT, M. Microfisica do poder. 21. ed. Rio de Janeiro: Graal, 2005.

FRAGA, A. B. Anatomias do consumo: investimentos na musculatura masculina. Educação \& Realidade, v. 25, n. 2, p. 135-150, jul./dez. 2000.

GUARESCHI, P.; BIZ, O. Mídia, Educação e Cidadania. Petrópolis, RJ: Vozes, 2005.

GUERRA, I.; SOARES, E. A.; BURINI, R. C. Aspectos nutricionais do futebol de competição. Revista Brasileira de Medicina do Esporte, Rio de Janeiro, v. 7, n. 6, p. 200-206, nov./dez. 2001.

GUERRA, M. O. O jogo da moda: a transformação do futebol em negócio. In: CONGRESSO BRASILEIRO DE CIÊNCIAS DA COMUNICAÇÃO, 28., 2005, Rio de Janeiro. Anais... São Paulo: Intercom, 2005. CD-ROM.

HABEMUS Pato. Zero Hora. Porto Alegre, 21 nov. 2006. Caderno de Esportes, p. 44.

LÁ vem o Pato. Zero Hora, Porto Alegre, 27 nov. 2006. Caderno de Esportes, p. 47.

LEONCINI, M. P.; SILVA, M. T. Entendendo o futebol como um negócio: um estudo exploratório. Gestão e Produção, v. 12, n. 1, p. 11-23, jan.-abr. 2005. 
LIPOVETSKY, G. Os tempos Hipermodernos. São Paulo: Barcarolla, 2004.

MANUAL das celebridades, O. Zero Hora, Porto Alegre, p. 52, 27 nov. 2006.

MEU nome é Pato. Zero Hora, Porto Alegre: 27 nov. 2006. Caderno de Esportes, p. 48.

PELBART, P. P. Vida capital: ensaios de biopolítica. São Paulo: Iluminares, 2003.

PILOTTO, F. M. A fabricação de ídolos esportivos. Revista Brasileira de Educação - ANPED, Rio de Janeiro, n. 23, p. 1-17, maio/jun./jul. 2003.

POWERS, S. K.; HOWLEY, E. T. Fisiologia do Exercício: teoria e aplicação ao condicionamento e ao desempenho. 3. ed. São Paulo: Manole, 2000.

PREMIAÇÕES da copa do mundo de 2006 somam R\$ 560 milhões. Folha de São Paulo, 05 jul. 2006. Caderno de esportes. Disponível em: <www1.folha.uol. com.br/folha/esporte/ult92u105404.shtml>. Acesso em: 25 de ago. 2013.

RECOMENDAÇÃO. Zero Hora, Porto Alegre, 25 nov. 2006. Caderno de Esportes, p. 50.

SIMPSON, A. Xuxa. São Paulo: Sumaré, 1994.

SURGE uma estrela. Zero Hora, Porto Alegre, 27 nov. 2006. Caderno de Esportes, p. 11.

VERDADEIRO Pato, O. Zero Hora, Porto Alegre, 25 nov. 2006. Caderno de Esportes, p. 46.

VIRILIO, P. A arte do motor. São Paulo: Estação Liberdade, 1996 .

VIRILIO, P. Velocidade e política. São Paulo: Estação Liberdade, 1996 b.

WEINBERG, R. S.; GOULD, D. Fundamentos da Psicologia do Esporte e do Exercício. 2. ed. Porto Alegre: Artmed, 2001.

Recebido em: 26 de outubro de 2013

Aceito em: 23 de julho de 2014 